\title{
Vibration uncoupling of germanium with different valence states lowers thermal conductivity of $\mathrm{Cs}_{2} \mathrm{Ge}_{3} \mathrm{Ga}_{6} \mathrm{Se}_{14}$
}

\author{
$\mathrm{Ni} \mathrm{Ma}{ }^{1}$, Lin Xiong ${ }^{2}$, Ling Chen ${ }^{1^{*}}$ and Li-Ming $\mathrm{Wu}^{2^{*}}$
}

\begin{abstract}
The thermal phonon transport is a key matter for heat managing in materials science which is crucial for device miniaturization and power density increase. Herein, we report the synthesis, structure and characterization of a new compound, $\mathrm{Cs}_{2} \mathrm{Ge}_{3} \mathrm{Ga}_{6} \mathrm{Se}_{14}$, with a unique anisotropic structure simultaneously containing $\mathrm{Ge}^{3+}$ and $\mathrm{Ge}^{2+}$ that adopt $(\mathrm{Ge} 1)^{3+}{ }_{2} \mathrm{Se}_{6}$ dimer or $(\mathrm{Ge} 2)^{2+} \mathrm{Se}_{6}$ octahedron, respectively. The thermal conductivity was measured to be $0.57-0.48 \mathrm{~W} \mathrm{~m}^{-1} \mathrm{~K}^{-1}$ from 323 to $773 \mathrm{~K}$, the lowest value among all the known Ge-containing compounds, approaching its glass limit according to the Cahill's formulation. More importantly, we discover for the first time that the vibration uncoupling of Ge with different valence states hinders the effective thermal energy transport between the $(\mathrm{Ge} 1)^{3+}{ }_{2} \mathrm{Se}_{6}$ dimer and $(\mathrm{Ge} 2)^{2+} \mathrm{Se}_{6}$ octahedron, and consequently lowers the thermal conductivity. In addition, we propose a structure factor $f_{i}=\sin (180-\beta) \times d_{\mathrm{Ge}-\mathrm{Q}} / l_{i}(i=\mathrm{A}, \mathrm{B})$, with which a structure map of the $\mathrm{Cs}_{2} \mathrm{Ge}_{3} \mathrm{M}_{6} \mathrm{Q}_{14}$ family is given.
\end{abstract}

Keywords: $\mathrm{Cs}_{2} \mathrm{Ge}_{3} \mathrm{Ga}_{6} \mathrm{Se}_{14}$, mixed valence states compound, thermal conductivity, phonon transport, crystallography analyses

\section{INTRODUCTION}

Heat managing is of great importance owing to the urgent needs of the miniaturization and increasing power density in modern devices [1]. Thus, the understanding of phonon thermal transport has become a key issue in materials science for engineering efficient materials towards applications. Chalcogenides, as promising functional materials with abundant compositions, crystal structures and property diversities, have shown the im- pressive potential applications, such as optoelectronics [2], transistors [3], and thermoelectrics [4]. In particular, the correlation between thermal property and the structure has been widely reported. For instance, studies on $\mathrm{AgPb}_{m} \mathrm{SbTe}_{2+m}$ [5], $\mathrm{Sn}_{1-x} \mathrm{In}_{x} \mathrm{Cd}_{x / 2} \mathrm{Te}$ [6], $\mathrm{Bi}_{2} \mathrm{Te}_{2.7} \mathrm{Se}_{0.3}$ [7], and $\mathrm{Pb}_{0.95}\left(\mathrm{Sb}_{0.033} \square_{0.017}\right) \mathrm{Se}_{1-y} \mathrm{Te}_{y}(\square=$ vacancy; $y=0-0.4)$ [8] show multiple defects that involve point defects, vacancy-driven dense dislocations, and Te-induced nanoprecipitates, collectively scatter thermal phonons in a wide frequency region, making the lattice thermal conductivity as low as $0.4 \mathrm{~W} \mathrm{~m}^{-1} \mathrm{~K}^{-1}$ and even reach its amorphous limit.

The common strategies toward low thermal conductivity mostly aim at alloying [9], hierarchical architectures [10], or nanostructuring [11], which tune the structure mechanically to scatter the phonon transport. Yet, these strategies face a challenge to ensure the repeatability and stability of the entire material system, not only in terms of structure, but also the thermal transport performance. From the chemistry point of view, the multivalent materials feature structure complexity due to various bonding nature and distinct local coordination geometries, and thus new routes should be offered to regulate the phonon propagation at atomic scale. However, related study is rare.

Germanium is a very interesting element with diverse valence states in one compound (Fig. 1). For instance, the $\mathrm{Ge}^{4+}$ tends to adopt a tetrahedral coordination with four nearly equidistant $\mathrm{Ge}-\mathrm{Q}(\mathrm{Q}=\mathrm{S}, \mathrm{Se}, \mathrm{Te})$ bonds [12-19], the $\mathrm{Ge}^{3+}$ usually forms a $\mathrm{Ge}-\mathrm{Ge}$ metal bond to fulfill its four coordination and generate the characteristic ethane-

\footnotetext{
${ }^{1}$ Beijing Key Laboratory of Energy Conversion and Storage Materials, College of Chemistry, Beijing Normal University, Beijing 100875, China

${ }^{2}$ Key Laboratory of Theoretical and Computational Chemistry of Ministry of Education, College of Chemistry, Beijing Normal University, Beijing 100875, China

* Corresponding authors (emails: chenl@bnu.edu.cn (Chen L); wlm@bnu.edu.cn (Wu LM))
} 


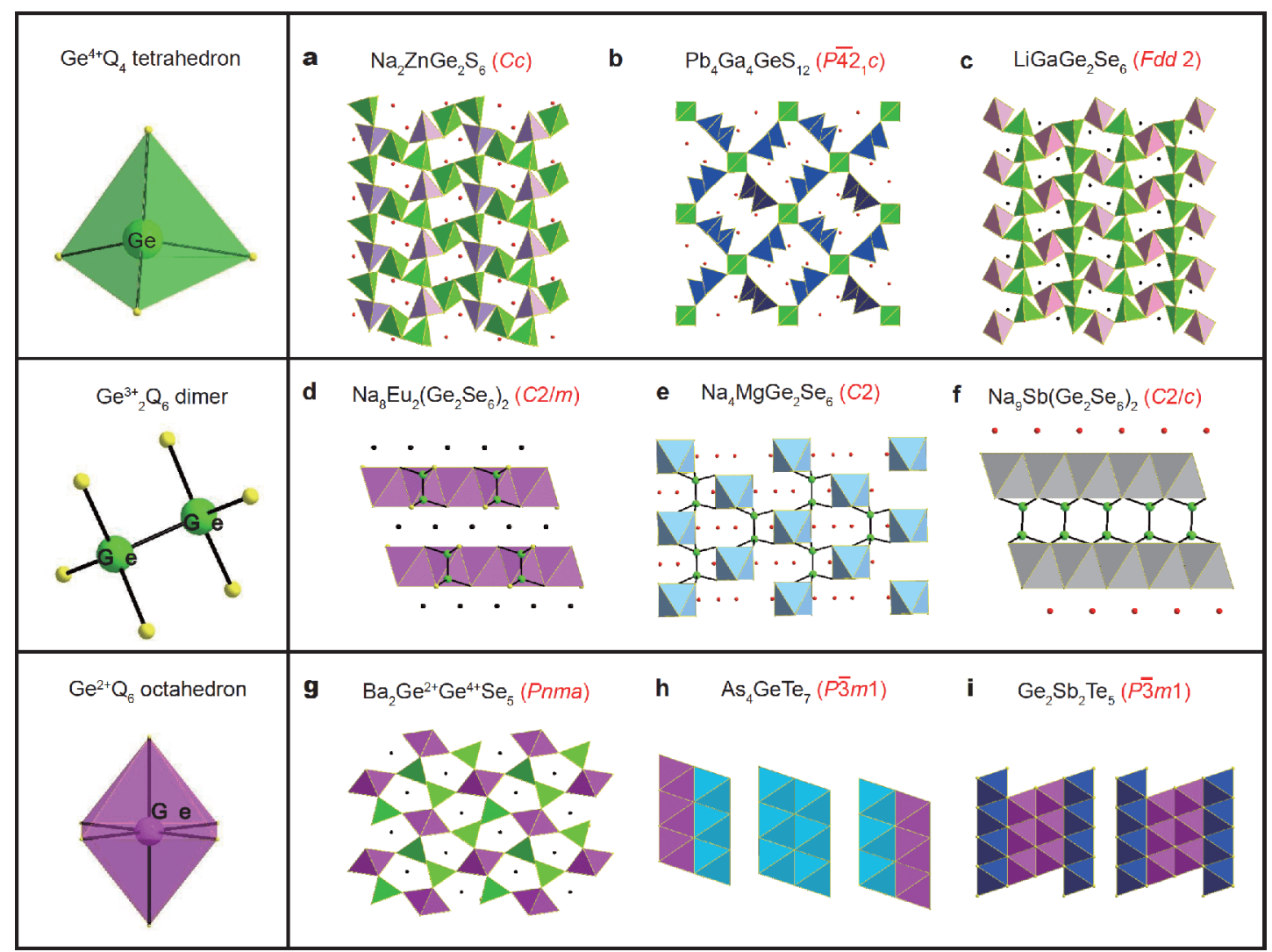

Figure 1 Representative compounds constructed by building units centered by Ge with different valence states: $\mathrm{Ge}^{4+} \mathrm{Q}_{4}$ tetrahedron $(\mathrm{a}-\mathrm{c})$, Ge ${ }_{2}{ }_{2} \mathrm{Q}_{6}$ dimers (d-f), and $\mathrm{Ge}^{2+} \mathrm{Q}_{6}$ octahedron (g-i), respectively.

like $\mathrm{Ge}^{3+}{ }_{2} \mathrm{Q}_{6}$ dimer [20-27], and the $\mathrm{Ge}^{2+}$ is often found in an octahedron with six Ge-Q bonds [27,30]. Various arrangements of these structure building units lead to great diversity of structures [13-30].

Herein, we report a new compound of the $\mathrm{Cs}_{2} \mathrm{Ge}_{3} \mathrm{M}_{6} \mathrm{Q}_{14}$ $(\mathrm{M}=\mathrm{Ga}$, In; $\mathrm{Q}=\mathrm{Se}, \mathrm{Te})$ family, $\mathrm{Cs}_{2} \mathrm{Ge}_{3} \mathrm{Ga}_{6} \mathrm{Se}_{14}$, in which $\mathrm{Ge}^{3+}$ and $\mathrm{Ge}^{2+}$ coexist. Single crystal diffraction data reveal that $\mathrm{Ge}$ with different valence states adopt $(\mathrm{Ge} 1)^{3+}{ }_{2} \mathrm{Se}_{6}$ dimer or $(\mathrm{Ge} 2)^{2+} \mathrm{Se}_{6}$ octahedron coordination, respectively. Importantly, we discover for the first time that the weak coupling of the vibrations of Ge atoms with different valence states hinders the effective thermal energy transport between the $(\mathrm{Ge} 1)^{3+}{ }_{2} \mathrm{Se}_{6}$ dimer and $(\mathrm{Ge} 2)^{2+} \mathrm{Se}_{6}$ octahedron which lowers the thermal conductivity. Consequently, the title compound exhibits thermal conductivity of $0.57-0.48 \mathrm{~W} \mathrm{~m}^{-1} \mathrm{~K}^{-1}$ from 323 to $773 \mathrm{~K}$, the lowest value among all the known Ge-containing compounds, approaching its glass limit according to the Cahill's formulation. In addition, we propose a structure factor $f_{i}=\frac{\sin (180-\beta) \times d_{\mathrm{Ge}-\mathrm{Q}}}{l_{i}}(i=\mathrm{A}, \mathrm{B})$, with which a structure map of the $\mathrm{Cs}_{2} \mathrm{Ge}_{3} \mathrm{M}_{6} \mathrm{Q}_{14}$ family is given.

\section{EXPERIMENTAL SECTION}

Synthesis of $\mathrm{Cs}_{2} \mathrm{Ge}_{3} \mathrm{Ga}_{6} \mathrm{Se}_{14}$

The compound was synthesized by a solid-state reaction of $\mathrm{CsCl}, \mathrm{Ge}, \mathrm{Ga}$ and Se with a molar ratio of 4:4:6:14 with slightly extra $\mathrm{Ge}$ and $\mathrm{CsCl}$ as reactive fluxes. After flamesealing inside a silica tubing, the reactant assembly was heated to $1173 \mathrm{~K}$ and kept at this temperature for $7500 \mathrm{~min}$, then slowly cooled to $573 \mathrm{~K}$ before shutting down the furnace. The yield was about $96 \%$. The lamellar dark-red crystals of $\mathrm{Cs}_{2} \mathrm{Ge}_{3} \mathrm{Ga}_{6} \mathrm{Se}_{14}$ are stable in air and insoluble in water.

\section{Thermal stabilities}

Simultaneous thermal analysis (STA) data were measured on a NETZSCH STA 449 F3 analyzer. Fig. S1d demonstrates the $\mathrm{Cs}_{2} \mathrm{Ge}_{3} \mathrm{Ga}_{6} \mathrm{Se}_{14}$ has good thermal stability with no evident weight loss up to $780^{\circ} \mathrm{C}$. Above $800^{\circ} \mathrm{C}$, $\mathrm{Cs}_{2} \mathrm{Ge}_{3} \mathrm{Ga}_{6} \mathrm{Se}_{14}$ decomposes to give $\mathrm{Ga}_{2} \mathrm{Se}_{3}$ (Fig. S1) (see 
more in Supplementary information).

\section{Single-crystal X-ray diffraction (XRD)}

The single crystal structure data of $\mathrm{Cs}_{2} \mathrm{Ge}_{3} \mathrm{Ga}_{6} \mathrm{Se}_{14}$ were collected on a Bruker APEX-II CCD diffractometer equipped with Mo Ka radiation $(\lambda=0.71073 \AA$ ) at room temperature. Full-matrix least-squares refinement on $F^{2}$ was carried out by using the SHELXTL program package [31]. Structure determination was based on the direct method and absorption correction was done by using multi-scan method, and then the structure was checked with PLATON [32] eventually.

\section{X-ray photoelectron spectroscopy (XPS)}

XPS (ESCSLAB 250Xi, USA) was used to investigate the surface properties. Fig. S1c indicates the bonding energies of 30.1 and $31.0 \mathrm{eV}$ are attributed to $\mathrm{Ge}^{2+}$ and $\mathrm{Ge}^{3+}$, respectively. An atomic ratio of $\mathrm{Ge}^{2+}: \mathrm{Ge}^{3+}=0.5: 1$ was calculated from the area of the XPS peak, in good agreement with the single crystal diffraction refinement results.

\section{Raman spectroscopy}

The Raman spectrum was collected on a RENISHAW RM 2000 spectrometer equipped with CCD detector using $532 \mathrm{~nm}$ laser.

\section{UV-vis diffuse reflectance spectra}

Diffuse-reflectance spectra were measured on a SHIMADZU UV-2600 Spectrometer in the range of 220 to $1400 \mathrm{~nm}$ at $293 \mathrm{~K}$. The UV-vis diffuse reflectance spectrum indicates an $E_{\mathrm{g}}=2.41 \mathrm{eV}$ (Fig. S1f).

\section{Ultrasonic pulse echo measurement}

The longitudinal and shear acoustic velocities were measured with a commercial equipment (Ultrasonic Pulser/Receiver Model 5058 PR, Olympus, USA) by counting the thickness of the sample $d$ and the traveling time $\Delta t$.

\section{Theoretical calculations}

The Vienna ab initio simulation package VASP [33] was performed to calculate the band structures and density of states (DOS). The generalized gradient approximation (GGA) was chosen as the exchange-correlation function and a plane wave basis with projector augmented wave (PAW) potentials was used [34-36]. Phonon calculation was carried out using Phonopy package [37] coded with VASP to estimate the lattice vibration, phonon dispersion and projected phonon density of states.

\section{Thermal transport measurement}

Single crystals of $\mathrm{Cs}_{2} \mathrm{Ge}_{3} \mathrm{Ga}_{6} \mathrm{Se}_{14}$ were ground into fine powder and densified by spark plasma sintering (SPS211LX). The obtained pellet has a density of $\sim 93 \%$ of the theoretical value. The total thermal conductivity was calculated by $\kappa=D \times C_{\mathrm{p}} \times d$, where the thermal diffusivity (D) was measured with a Netzsch LFA-457 and the specific heat $\left(C_{\mathrm{p}}\right)$ was indirectly measured with a reference of pyroceram 9606.

\section{RESULTS AND DISCUSSION}

\section{Synthesis and crystal growth of $\mathrm{Cs}_{2} \mathrm{Ge}_{3} \mathrm{Ga}_{6} \mathrm{Se}_{14}$}

The $\mathrm{Cs}_{2} \mathrm{Ge}_{3} \mathrm{Ga}_{6} \mathrm{Se}_{14}$ was successfully synthesized via a modified solid-state reaction. In the procedure, not only extra $\mathrm{CsCl}$ as a reactive flux, but also extra $\mathrm{Ge}$ (one of the reactants) with high melting point was purposely introduced, which successfully increased the heterogeneity and promoted the reaction with relatively high surface diffusion to significantly facilitate the single crystal growth [38-40]. The melting points of the reactants, $\mathrm{CsCl}, \mathrm{Ge}, \mathrm{Ga}$ and Se, are 918, 1211, 302 and $494 \mathrm{~K}$, respectively. Actually, the difficulty in the synthesis of the multinary alkali metal chalcogenide $\mathrm{Cs}_{2} \mathrm{Ge}_{3} \mathrm{Ga}_{6} \mathrm{Se}_{14}$ lies in not only the low reaction capacity with a low product yield about $10 \%$, but also the high stability of the byproduct $\mathrm{Ga}_{2} \mathrm{Se}_{3}$ that cannot be simply removed by distilled water or ethanol. To solve such problems, we first introduced extra amount of $\mathrm{CsCl}$ that served as a reactive flux in the reaction, which also helped to generate plenty of tiny single crystals with average sizes of $0.2 \times 0.2 \times$ $0.1 \mathrm{~mm}^{3}$ (Fig. S2a). Secondly, we further investigated the crystal growth process to increase the crystal size. Fig. S2b implies that prolonging the annealing time to $7500 \mathrm{~min}$ results in a single crystal size of $0.3 \times 0.3 \times 0.2 \mathrm{~mm}^{3}$. Significantly, the introduction of extra Ge with high melting point leads to a remarkable enhancement of the single crystal sizes up to $3 \times 3 \times 0.5 \mathrm{~mm}^{3}$ (Fig. S2c), almost 10 times larger than the first attempt. Since the complexity and particularity of solid state reaction and crystal growth, this approach may shed some useful light on other systems with similar crystal habit and crystal structure. The purity of $\mathrm{Cs}_{2} \mathrm{Ge}_{3} \mathrm{Ga}_{6} \mathrm{Se}_{14}$ was checked by the powder XRD patterns shown in Fig. S1a. Furthermore, the semi-quantitative element analyses (Fig. S3) confirm the stoichiometry with an average formula of $\mathrm{Cs}_{2} \mathrm{Ge}_{3.5(8)}-\mathrm{Ga}_{6.4(1)} \mathrm{Se}_{14.8(0)}$.

\section{Crystal structure and structure relationship}

$\mathrm{Cs}_{2} \mathrm{Ge}_{3} \mathrm{Ga}_{6} \mathrm{Se}_{14}$ crystallizes in space group $P \overline{3} m 1$ (No. 164) 
with unit cell parameters of $a=b=7.6396(3) \AA, c=$ 13.5866(6) $\AA, V=686.72(6) \AA^{3}$, and $Z=1$. Crystallographic data and refinement details are displayed in Tables S1-S3. The Ga atom locates at the Wyckoff site $6 i$ with a $\mathrm{GaSe}_{4}$ tetrahedron geometry to form a $\mathrm{Ga}_{6} \mathrm{Se}_{14}$ layer that further alternatively connects $\mathrm{Ge}^{3+}{ }_{2} \mathrm{Se}_{6}$ dimer and $\mathrm{Ge}^{2+} \mathrm{Se}_{6}$ octahedron generating a 3D structure with Cs atoms filling in the vacancies.

The $\mathrm{Ge}-\mathrm{Q}$ bonding nature determines the structure distribution of $\mathrm{Cs}_{2} \mathrm{Ge}_{3} \mathrm{M}_{6} \mathrm{Q}_{14}$ family, $\mathrm{Cs}_{2} \mathrm{Ge}_{3} \mathrm{In}_{6} \mathrm{Te}_{14}$, $\mathrm{Cs}_{2} \mathrm{Ge}_{3} \mathrm{Ga}_{6} \mathrm{Te}_{14}$, and $\mathrm{Cs}_{2} \mathrm{Ge}_{3} \mathrm{Ga}_{6} \mathrm{Se}_{14}$ take the $P \overline{3} m 1$-type structure, while $\mathrm{Cs}_{2} \mathrm{Ge}_{3} \mathrm{In}_{6} \mathrm{Se}_{14}$ crystallizes in the space group $R \overline{3} m$. There are two crystallographically different sites $\mathrm{A}$ and $\mathrm{B}$, confined by the Q-Q-Q triangle (Fig. 2c). When the $\mathrm{Ge}^{3+}{ }_{2} \mathrm{Se}_{6}$ dimer occupies the site $\mathrm{A}$, the compound adopts the $P \overline{3} m 1$ structure, otherwise the $R \overline{3} m$-type structure is taken. The $\mathrm{Ge}-\mathrm{Q}$ bond distance, $\mathrm{Ge}-\mathrm{Ge}-\mathrm{Q}$ bond angle in the $\mathrm{Ge}^{3+}{ }_{2} \mathrm{Q}_{6}$ dimer, and the size of the site $\mathrm{A}$ or $\mathrm{B}$ mainly drives the site preference, which determines the structure type. The size of site $A$ or $B$ is defined as the equivalent $\mathrm{Q}-\mathrm{Q}$ distance of $\mathrm{Q}-\mathrm{Q}-\mathrm{Q}$ triangle in the $\mathrm{M}_{6} \mathrm{Q}_{14}$ layer as listed in Table S4.

And a factor is defined as $f_{i}=\sin (180-\beta) \times$ $d_{\mathrm{Ge}-\mathrm{Q}} / l_{i}(i=\mathrm{A}, \mathrm{B})$, clearly showing how the two structure types distribute among the $\mathrm{Cs}_{2} \mathrm{Ge}_{3} \mathrm{M}_{6} \mathrm{Q}_{14}$ family, where
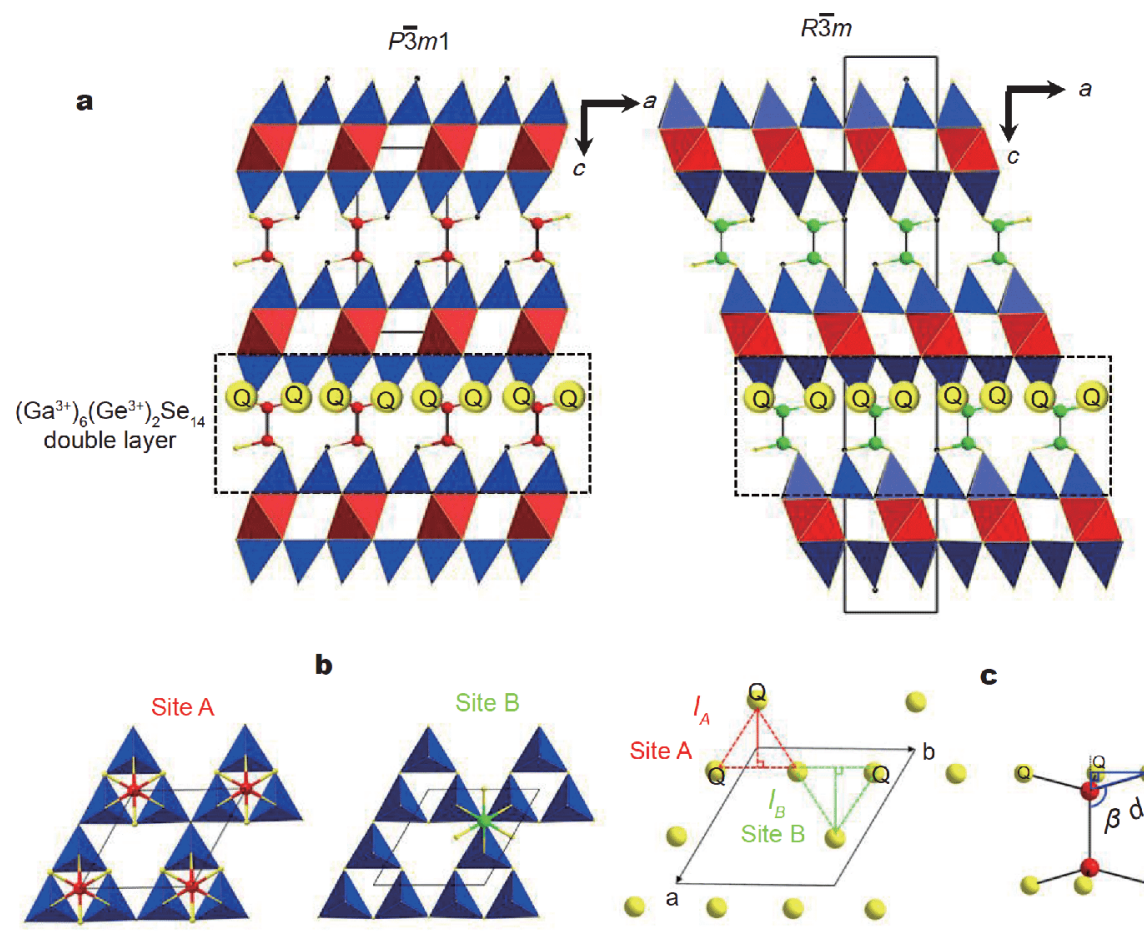

c

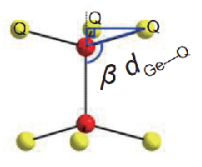

d
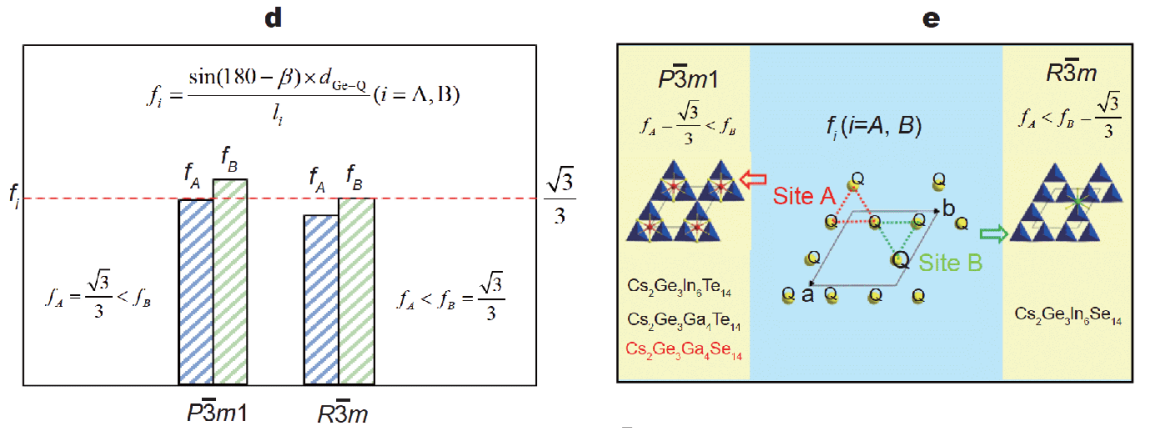

Figure 2 Crystal structure of $\mathrm{Cs}_{2} \mathrm{Ge}_{3} \mathrm{M}_{6} \mathrm{Q}_{14}$ family. (a) The views of the packing along the $b$ axis for the $P \overline{3} m 1$-type and $R \overline{3} m$-type structures. Red octahedron: $\mathrm{Ge}^{2+} \mathrm{Se}_{6}$, blue tetrahedron: $\mathrm{GaSe}_{4}$, ball and stick: $\mathrm{Ge}^{3+}{ }_{2} \mathrm{Se}_{6}$ dimer; (b) a single $\mathrm{M}_{6} \mathrm{Q}_{14}$ layer viewed on the $a b$ plane, site $\mathrm{A}$ or B is marked; (c) the $\mathrm{Q}-\mathrm{Q}-\mathrm{Q}$ triangle confines the site $\mathrm{A}$ and $\mathrm{B}$, with the edge marked as $l_{i}(i=\mathrm{A}, \mathrm{B})$, the $\mathrm{Ge}^{3+}{ }_{2} \mathrm{Q}_{6}$ dimer with the Ge-Q bond length $\left(d_{\mathrm{Ge}-\mathrm{Q}}\right)$ and the $\mathrm{Ge}-$ Ge-Q angle $(\beta)$ labeled; (d) the definition of the factor of $f_{i}$; and (e) the structure map classified by the $f_{i}$ factor. 
$d_{\mathrm{Ge}-\mathrm{Q}}$ represents the $\mathrm{Ge}-\mathrm{Q}$ bond distance, $\beta$ is the bond angle of $\mathrm{Ge}-\mathrm{Ge}-\mathrm{Q}, l_{i}$ represents the distance of $\mathrm{Q}-\mathrm{Q}$. The factor $f_{i}=\frac{\sqrt{3}}{3}$ indicates the projection of three Ge-Q bonds of the $\mathrm{Ge}^{3+}{ }_{2} \mathrm{Q}_{6}$ dimer rightly crosses in the center of site A or B. When $f_{A}=\frac{\sqrt{3}}{3}<f_{B}$, the $\mathrm{Ge}^{3+}{ }_{2} \mathrm{Q}_{6}$ dimer will choose the larger site $\mathrm{A}$ instead of the smaller site $\mathrm{B}$, and the compound will adopt the $P \overline{3} m 1$-type structure, when $f_{A}<f_{B}=\frac{\sqrt{3}}{3}$, the site $\mathrm{A}$ is too large to accommodate the $\mathrm{Ge}^{3+}{ }_{2} \mathrm{Q}_{6}$ dimer, which will occupy the site $\mathrm{B}$ instead and then generates the $R 3 m$-type structure (Fig. 2d). For $\mathrm{Cs}_{2} \mathrm{Ge}_{3} \mathrm{Ga}_{6} \mathrm{Se}_{14}$, the site $\mathrm{A}$ is more tolerable for the $\mathrm{Ge}^{3+}{ }_{2} \mathrm{Se}_{6}$ dimer, with a $l_{\mathrm{A}}$ of $3.9571 \AA$ about $7 \%$ larger than that of site $\mathrm{B}$. As a result, $\mathrm{Cs}_{2} \mathrm{Ge}_{3} \mathrm{Ga}_{6} \mathrm{Se}_{14}$ adopts the space group $P \overline{3} m 1$.

\section{Thermal transport property}

The density of SPS-densified $\mathrm{Cs}_{2} \mathrm{Ge}_{3} \mathrm{Ga}_{6} \mathrm{Se}_{14}$ pellet reaches $4.5 \mathrm{~g} \mathrm{~cm}^{-3}$, about $\sim 93 \%$ of the theoretical value. The thermal conductivity was obtained by the formula $\kappa=D$ $\times C_{\mathrm{p}} \times d$, where thermal diffusivity $(D)$ measured in the temperature range of $323-773 \mathrm{~K}$ and the specific heat $\left(C_{\mathrm{p}}\right)$ was indirectly counted by the reference of pyroceram 9606. Fig. 3d depicts the thermal conductivity $(\kappa)$ of $\mathrm{Cs}_{2} \mathrm{Ge}_{3} \mathrm{Ga}_{6} \mathrm{Se}_{14}$, the very low value of $0.57-0.48 \mathrm{~W} \mathrm{~m}^{-1} \mathrm{~K}^{-1}$ from 323 to $773 \mathrm{~K}$ is striking. This value is competitive to those Ge-containing thermal conductive dense solids, such as two representatives of the mid-IR nonlinear optical material $\mathrm{ZnGeP}_{2}[41]$ and short-period superlattice Ge [42], respectively, showing large thermal conductivities of 35 and $70 \mathrm{~W} \mathrm{~m}^{-1} \mathrm{~K}^{-1}$ at $300 \mathrm{~K}$, which are at least 70 times larger than that of the title compound. Moreover, compared with other Ge-based thermoelectric materials, such as GeSe $\left(1.6-0.8 \mathrm{~W} \mathrm{~m}^{-1} \mathrm{~K}^{-1}, 300-570 \mathrm{~K}\right)$ [43], $\mathrm{Cu}_{2} \mathrm{ZnGeSe}_{4}\left(1.0-0.8 \mathrm{~W} \mathrm{~m}^{-1} \mathrm{~K}^{-1}, 300-723 \mathrm{~K}\right)$ [44], $\mathrm{K}_{8} \mathrm{Ga}_{8} \mathrm{Ge}_{38}\left(0.9-1.3 \mathrm{~W} \mathrm{~m}^{-1} \mathrm{~K}^{-1}, 100-300 \mathrm{~K}\right)$ [45], $\mathrm{Cu}_{22^{-}}$ $\mathrm{Fe}_{8} \mathrm{Ge}_{4} \mathrm{Se}_{32}\left(1.7-1.2 \mathrm{~W} \mathrm{~m}^{-1} \mathrm{~K}^{-1}, 300-570 \mathrm{~K}\right)$ [46], $\mathrm{Ag}_{6^{-}}$ $\mathrm{Ge}_{10} \mathrm{P}_{12}\left(1.2-1.0 \mathrm{~W} \mathrm{~m}^{-1} \mathrm{~K}^{-1}, 300-700 \mathrm{~K}\right)$ [47], $\mathrm{Ba}_{24} \mathrm{Ge}_{100}$ $\left(2.8-3.8 \mathrm{~W} \mathrm{~m} \mathrm{~K}^{-1}, \quad 300-750 \mathrm{~K}\right)$ [48], $\mathrm{Cu}_{2} \mathrm{ZnGeSe}_{4}$ (3.2-1.0 W m $\left.\mathrm{K}^{-1} \quad \mathrm{~K}^{-1}, \quad 300-670 \mathrm{~K}\right)$ [49], $\mathrm{Cu}_{2} \mathrm{ZnGeS}_{4}$ (3.8-1.2 W m $\left.{ }^{-1} \mathrm{~K}^{-1}, \quad 300-670 \mathrm{~K}\right)$ [49], $\mathrm{Ba}_{2} \mathrm{Cr}_{4} \mathrm{GeSe}_{10}$ (0.8-0.6 W m $\left.{ }^{-1} \mathrm{~K}^{-1}, 300-770 \mathrm{~K}\right)$ [50], $\mathrm{Cs}_{2} \mathrm{Ge}_{3} \mathrm{Ga}_{6} \mathrm{Se}_{14}$ possesses an extreme lower thermal conductivity which makes it stand out. Note that the majority of the Ge-based compounds only contain $\mathrm{Ge}$ with single valence state. Differently, $\mathrm{Cs}_{2} \mathrm{Ge}_{3} \mathrm{Ga}_{6} \mathrm{Se}_{14}$ owns structural complexity with mixed valence states $\left(\mathrm{Ge}^{2+}, \mathrm{Ge}^{3+}\right)$. The room temperature ultrasonic measurement was carried out to ex- plore the origin of the low thermal conductivity. The lattice vibration, coupled with the long wavelengths and the acoustic phonons propagation speeds, mainly governs the thermal conduction in materials. The acoustic phonons velocity therefore is a key measure of the lattice thermal conduction behavior. The ultrasonic pulse echo measurements show the longitudinal and transverse sound velocities of $v_{1}=2811 \mathrm{~ms}^{-1}$ and $v_{\mathrm{s}}=1680 \mathrm{~ms}^{-1}$, respectively. Theoretical elastic property calculations of the average sound velocity $v_{\mathrm{a}}$, Young's modulus $E$, shear modulus $G$, Poisson ratio $v_{\mathrm{p}}$, and Grüneisen parameter $\gamma$ are obtained according to the following equations $[51,52]$ :

$v_{\mathrm{a}}=\left[\frac{1}{3}\left(\frac{1}{v_{1}^{3}}+\frac{2}{v_{\mathrm{s}}^{3}}\right)\right]^{-1 / 3}$,

$E=\frac{\rho v_{\mathrm{s}}^{2}\left(3 v_{1}^{2}-4 v_{\mathrm{s}}^{2}\right)}{v_{1}^{2}-v_{\mathrm{s}}^{2}}$,

$G=\frac{E}{2\left(1+v_{\rho}\right)}$

$v_{\rho}=\frac{1-2\left(v_{\mathrm{s}} / v_{1}\right)^{2}}{2-2\left(v_{\mathrm{s}} / v_{1}\right)^{2}}$

$\gamma=\frac{3}{2}\left(\frac{1+v_{\rho}}{2-3 v_{\rho}}\right)$.

As listed in Table 1, all the positive elastic constants reveal the mechanical stability of this compound. The low transverse sound velocity of $1680 \mathrm{~ms}^{-1}$, indicates the soft shear modes scarcely propagate through the lattice, which gives rise to the low $\kappa$ in $\mathrm{Cs}_{2} \mathrm{Ge}_{3} \mathrm{Ga}_{6} \mathrm{Se}_{14}$. In addition, the longitudinal sound velocity of $2811 \mathrm{~ms}^{-1}$ also features a distinct low value in comparison with the general reported materials with low thermal conductivity [53-55]. And the relatively low average sound velocity of $1859 \mathrm{~ms}^{-1}$ leads to the low Young's modulus (33.48 GPa) and Shear modulus (13.69 GPa). Besides, the Debye temperature $\theta_{\mathrm{D}}$ is calculated [52]:

$\theta_{\mathrm{D}}=\frac{h}{k_{\mathrm{B}}}\left[\frac{3 N}{4 \pi V}\right]^{1 / 3} v_{\mathrm{a}}$

where $V$ represents the volume of unit cell, $N$ is the number of atoms in the unit cell, and $v_{a}$ indicates the average sound velocity. The low Debye temperature $183.49 \mathrm{~K}$ and the relatively large Grüneisen parameter $\gamma$ 1.37 , which is comparable to majority of the state-of-theart thermoelectric materials with $\gamma=1.0-2.6$ [56], illustrate the thermal transport behavior in a way. All these results support the low thermal conductivity $\kappa$ observed in $\mathrm{Cs}_{2} \mathrm{Ge}_{3} \mathrm{Ga}_{6} \mathrm{Se}_{14}$. The strong temperature-dependence of 

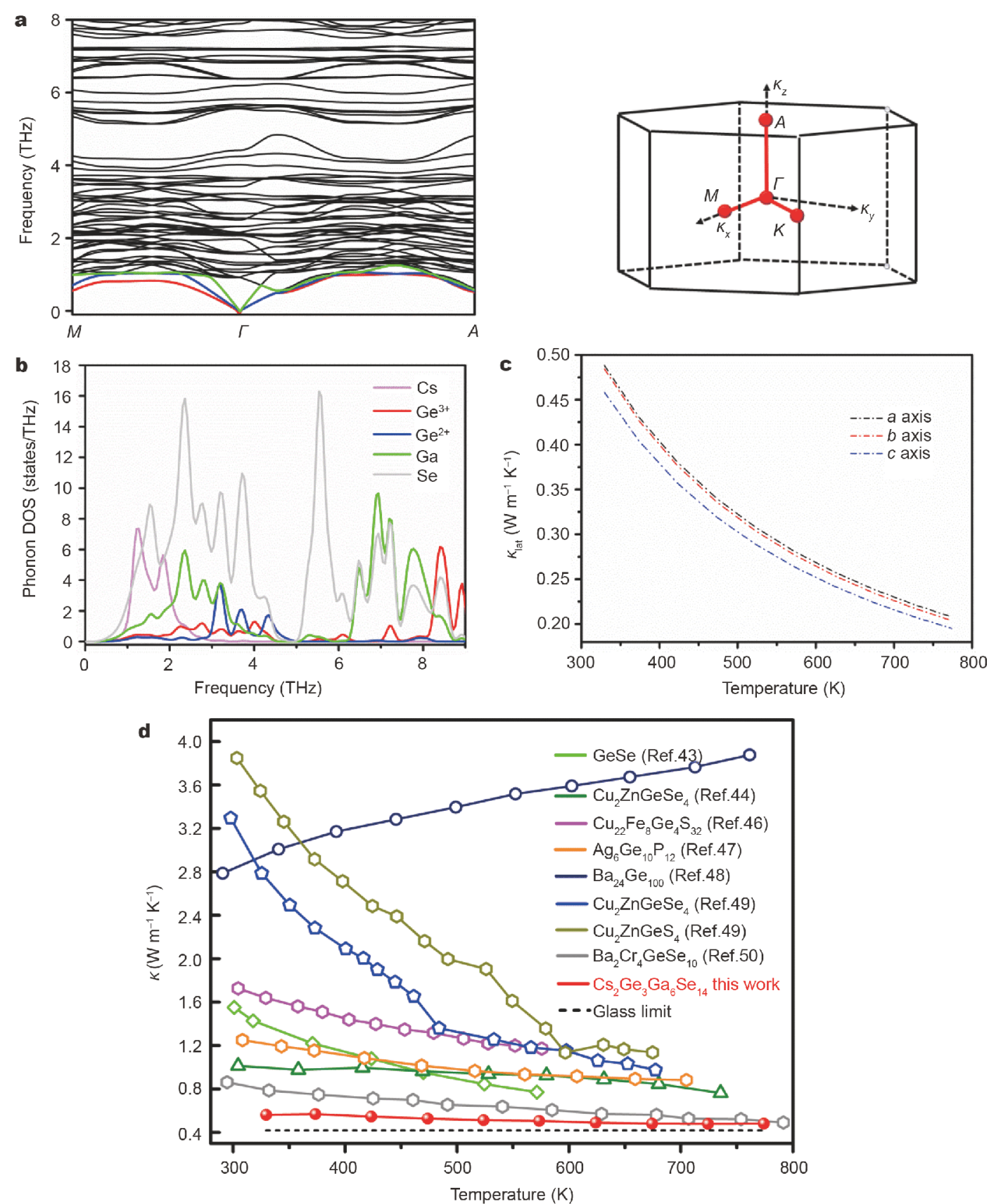

Figure 3 Thermal transport properties of $\mathrm{Cs}_{2} \mathrm{Ge}_{3} \mathrm{Ga}_{6} \mathrm{Se}_{14}$. (a) Theoretically calculated phonon dispersion. Red, blue: the transverse acoustic phonon scattering branches TA and TA', green: the longitudinal acoustic phonon models (LA). (b) The projected partial phonon density of states. (c) The calculated lattice thermal conductivity along three crystal axes. (d) The measured temperature-dependent thermal conductivity. Some Ge-containing binary and multinary materials are also listed. The black dotted line: the glass limit of the lattice thermal conductivity in $\mathrm{Cs}_{2} \mathrm{Ge}_{3} \mathrm{Ga}_{6} \mathrm{Se}_{14} \mathrm{according}$ to the Cahill's formulation.

the thermal conductivity in $\mathrm{Cs}_{2} \mathrm{Ge}_{3} \mathrm{Ga}_{6} \mathrm{Se}_{14}$ indicates a typical crystal behavior (Fig. 3). Since the $E_{\mathrm{g}}=2.41 \mathrm{eV}$ (Fig. S1f), the carries thermal conductivity is negligible in $\mathrm{Cs}_{2} \mathrm{Ge}_{3} \mathrm{Ga}_{6} \mathrm{Se}_{14}$, and the measured thermal conductivity can be roughly treated as the lattice thermal conductivity.
On the basis of density function theory (DFT) phonon calculation of $\mathrm{Cs}_{2} \mathrm{Ge}_{3} \mathrm{Ga}_{6} \mathrm{Se}_{14}$, lattice dynamical properties trigger better understanding of its ultralow thermal conductivity. Various chemical bonding interactions and diverse geometries in a solid crystalline material cause 
Table 1 The measured sound velocity $v_{1}, v_{\mathrm{s}}, v_{\mathrm{a}}$, elastic properties $\left(E, G, v_{\mathrm{p}}\right)$, Grüneisen parameter $(\gamma)$ and Debye temperature $\left(\theta_{\mathrm{D}}\right)$ for $\mathrm{Cs}_{2} \mathrm{Ge}_{3} \mathrm{Ga}_{6} \mathrm{Se}_{14}$ at room temperature

\begin{tabular}{cc}
\hline Parameters & $\mathrm{Cs}_{2} \mathrm{Ge}_{3} \mathrm{Ga}_{6} \mathrm{Se}_{14}$ \\
\hline Longitudinal sound velocity, $v_{\mathrm{l}}\left(\mathrm{m} \mathrm{s}^{-1}\right)$ & 2811 \\
Transverse sound velocity, $v_{\mathrm{s}}\left(\mathrm{m} \mathrm{s}^{-1}\right)$ & 1680 \\
Average sound velocity, $v_{\mathrm{a}}\left(\mathrm{m} \mathrm{s}^{-1}\right)$ & 1859 \\
Young's modulus, $E(\mathrm{GPa})$ & 33.48 \\
Shear modulus, $G(\mathrm{GPa})$ & 13.69 \\
Poisson ratio, $v_{\mathrm{p}}$ & 0.22 \\
Grüneisen parameter, $\gamma$ & 1.37 \\
Debye temperature, $\theta_{\mathrm{D}}(\mathrm{K})$ & 183.49 \\
\hline
\end{tabular}

quite flat phonon dispersion as shown in Fig. 3a, demonstrating its thermodynamic stability with no imaginary eigenvalue observed. Indeed, the various structure geometries and bonding natures of $(\mathrm{Ge} 2)^{2+} \mathrm{Se}_{6}$ octahedron, $(\mathrm{Ge} 1)^{3+}{ }_{2} \mathrm{Se}_{6}$ dimer, and $\mathrm{GaSe}_{4}$ tetrahedron in $\mathrm{Cs}_{2} \mathrm{Ge}_{3} \mathrm{Ga}_{6} \mathrm{Se}_{14}$, contribute quite differently to the heat propagation. The $(\mathrm{Ge} 2)^{2+} \mathrm{Se}_{6}$ octahedron exhibits high symmetry with six equivalent Ge-Se bonds of $2.86 \AA$, and the long interatomic distance between $(\mathrm{Ge} 2)^{2+}$ and Se illustrates the weak chemical bonding, which coupled with its discrete inter-octahedron arrangement motif in the structure (Fig. 2a) give rise to the strong disruption of the heat propagation. Differently, the four-fold coordinated $(\mathrm{Ge} 1)^{3+}$ shows a dimeric structure with three Ge-Se bonds of $2.35 \AA$ and a Ge-Ge metallic bond of $2.41 \AA$. In addition, $\mathrm{Ga}^{3+}$ is four coordinated in the $\mathrm{GaSe}_{4}$ tetrahedron with $\mathrm{Ga}-\mathrm{Se}$ bond length range from 2.39 to $2.40 \AA$, and shares the tetrahedral vertexes to generate the $\mathrm{Ga}_{6} \mathrm{Se}_{14}$ layer that is parallel to the $a b$ plane. Owing to the similar bonding nature, same valence state, same coordination geometry, comparable bond length, and reduced mass, the $(\mathrm{Ge} 1)^{3+}{ }_{2} \mathrm{Se}_{6}$ dimer and the $\mathrm{Ga}^{3+} \mathrm{Se}_{4}$ tetrahedron exhibit strong coupling interaction as shown in Fig. 3b with similar curve shape at the lower frequencies region that contributes more to the heat transport. Thus, $\mathrm{Cs}_{2} \mathrm{Ge}_{3} \mathrm{Ga}_{6} \mathrm{Se}_{14}$ features a $\left(\mathrm{Ga}^{3+}\right)_{6}\left(\mathrm{Gel}^{3+}\right)_{2} \mathrm{Se}_{14}$ double layer motif that runs parallel to the $a b$ plane. On the other hand, the inter-atomic $(\mathrm{Ge} 1)^{3+} /(\mathrm{Ga})^{3+}$-Se distance of 2.35-2.41 $\AA$ is much shorter than the distance of $(\mathrm{Ge} 2)^{2+}-\mathrm{Se}=2.86 \AA$ between adjacent double layers, convincing that the heat propagation is strongly restrained along the $c$ axis direction perpendicular to the $\left(\mathrm{Ga}^{3+}\right)_{6}\left(\mathrm{Ge}^{3+}\right)_{2} \mathrm{Se}_{14}$ double layers. And $(\mathrm{Ge} 2)^{2+}$ transports less heat supported by the phonon density of states shown in Fig. 3b, where the phonon frequencies of $(\mathrm{Ge} 2)^{2+}$ locate at the higher frequency region than that of $\mathrm{Ga}^{3+}$ and
$(\mathrm{Ge} 1)^{3+}$. The isolated Cs atoms are strongly rattling within the spacious vacancies (with size up to $4.04 \AA$ ) evidenced by the lower lying $\mathrm{Cs}^{+}$phonon states. The $\mathrm{Cs}^{+}$highly localized at the lower frequency (Fig. 3b), greatly contributes to the ultralow lattice thermal conductivity of the compound. According to all analyses above, the structure complicity in $\mathrm{Cs}_{2} \mathrm{Ge}_{3} \mathrm{Ga}_{6} \mathrm{Se}_{14}$ leads to the large lattice anharmonicity and the ultralow lattice thermal conductivity. The heat anisotropically propagates with much lower lattice thermal conductivity along the $c$ direction that is perpendicular to the $\left(\mathrm{Ga}^{3+}\right)_{6}\left(\mathrm{Ge}^{3+}\right)_{2} \mathrm{Se}_{14}$ double layer. This is supported by the Slack model DFT thermodynamics calculations [57], $\kappa_{l}$ (along $c$ ) $<\kappa_{l}$ (along $b$ ) $\approx \kappa_{l}$ (along $a$ ) (Fig. 3c). Furthermore, the phonon mean free path $l$ is roughly estimated according to the relationship $\kappa_{l}=C_{\mathrm{v}} v_{\mathrm{a}} / / 3$ by using the calculated lattice thermal conductivity $\kappa_{l}$ along the $a$ axis, the observed average sound velocity $v_{\mathrm{a}}$, and the heat capacity at constant volume. The estimated small phonon mean free path $(l)$ of $2.40 \AA$ at $300 \mathrm{~K}$ is quite close to the bond length of $(\mathrm{Ge} 1)^{3+}-\mathrm{Se}=2.35 \AA$, and $\mathrm{Ga}-\mathrm{Se}=2.39 \AA$, indicating the $(\mathrm{Ge} 1)^{3+}{ }_{2} \mathrm{Se}_{6}$ dimer and $\mathrm{Ga}^{3+} \mathrm{Se}_{4}$ tetrahedron mainly contribute to the low lattice thermal conductivity in the $a b$ plane. In short, the relatively large number of atoms in unit cell of $\mathrm{Cs}_{2} \mathrm{Ge}_{3} \mathrm{Ga}_{6} \mathrm{Se}_{14}$ (25 atoms per unit), small volume of the first Brillouin zone coupled with the unique rattling modes, large lattice anharmonicity, and structure complexity, are all responsible for the extremely low lattice thermal conductivity of the compound. Usually, glass exhibits the minimum thermal conductivity because the heat propagates by a random pathway through the sublattice of phonons rather than a smooth transport behavior as in a crystalline media. And the glass limit $\kappa_{\min }$ for the lattice thermal conductivity of $\mathrm{Cs}_{2} \mathrm{Ge}_{3} \mathrm{Ga}_{6} \mathrm{Se}_{14}$ can be estimated by using the measured longitudinal and transverse sound velocities based on the Cahill's formula [58],

$\kappa_{\min }=\frac{1}{2}\left(\frac{\pi}{6}\right)^{1 / 3} \kappa_{B} V^{-2 / 3}\left(2 \vartheta_{\mathrm{s}}+\vartheta_{1}\right)$.

The Cahill estimation utilizes a summation of all sound modes with the associated sound speed. And the slight lower value of the glass limit, $0.43 \mathrm{~W} \mathrm{~m}^{-1} \mathrm{~K}^{-1}$, implies an ultralow lattice thermal conductivity for $\mathrm{Cs}_{2} \mathrm{Ge}_{3} \mathrm{Ga}_{6} \mathrm{Se}_{14}$, and also the fact that the lattice vibration is the major contribution of the total thermal transport.

\section{CONCLUSIONS}

In summary, the synthesis, single crystal structure and thermal transport properties of $\mathrm{Cs}_{2} \mathrm{Ge}_{3} \mathrm{Ga}_{6} \mathrm{Se}_{14}$ were stu- 
died. Single crystal diffraction data reveal that Ge with different valence states adopts $(\mathrm{Ge} 1)^{3+}{ }_{2} \mathrm{Se}_{6}$ dimer, or $(\mathrm{Ge} 2)^{2+} \mathrm{Se}_{6}$ octahedron, respectively. The thermal conductivity was measured to be $0.57-0.48 \mathrm{~W} \mathrm{~m}^{-1} \mathrm{~K}^{-1}$ from 323 to $773 \mathrm{~K}$, the lowest value among all the known Gecontaining compounds, approaching its glass limit according to the Cahill's formulation. The ab initio phonon dispersion and single crystal structure analyses reveal for the first time that the vibration uncoupling of Ge with different valence states hinders the effective thermal energy transport between the $(\mathrm{Ge} 1)^{3+}{ }_{2} \mathrm{Se}_{6}$ dimer and $(\mathrm{Ge} 2)^{2+} \mathrm{Se}_{6}$ octahedron. Such a previously unknown uncoupling, together with the well-known Cs-rattling feature lead to the ultralow thermal conductivity of $\mathrm{Cs}_{2} \mathrm{Ge}_{3} \mathrm{Ga}_{6} \mathrm{Se}_{14}$. In addition, we propose a structure factor $f_{i}=\frac{\sin (180-\beta) \times d_{\mathrm{Ge}-\mathrm{Q}}}{l_{i}}(i=\mathrm{A}, \mathrm{B})$, with which a structure map of the $\mathrm{Cs}_{2} \mathrm{Ge}_{3} \mathrm{M}_{6} \mathrm{Q}_{14}$ family is given, where if $f_{A}=\frac{\sqrt{3}}{3}$, compound adopts the $P \overline{3} m 1$ symmetry, if $f_{B}=\frac{\sqrt{3}}{3}$, the $R \overline{3} m$ space group will be adopted.

\section{Received 23 August 2019; accepted 23 September 2019;} published online 25 October 2019

$1 \mathrm{Xu} \mathrm{X}$, Chen J, Li B. Phonon thermal conduction in novel 2D materials. J Phys-Condens Matter, 2016, 28: 483001-483021

2 Ummadisingu A, Steier L, Seo JY, et al. The effect of illumination on the formation of metal halide perovskite films. Nature, 2017, 545: $208-212$

3 Island JO, Molina-Mendoza AJ, Barawi M, et al. Electronics and optoelectronics of quasi-1D layered transition metal trichalcogenides. 2D Mater, 2017, 4: 022003

4 Chung DY, Hogan T, Brazis P, et al. $\mathrm{CsBi}_{4} \mathrm{Te}_{6}$ : a high-performance thermoelectric material for low-temperature applications. Science, 2000, 287: 1024-1027

5 Hsu KF, Loo S, Guo F, et al. Cubic $\mathrm{AgPb}_{m} \mathrm{SbTe}_{2+m}$ : bulk thermoelectric materials with high figure of merit. Science, 2004, 303: $818-821$

6 Tan G, Shi F, Hao S, et al. Codoping in SnTe: enhancement of thermoelectric performance through synergy of resonance levels and band convergence. J Am Chem Soc, 2015, 137: 5100-5112

7 Soni $\mathrm{A}$, Shen $\mathrm{Y}$, Yin M, et al. Interface driven energy filtering of thermoelectric power in spark plasma sintered $\mathrm{Bi}_{2} \mathrm{Te}_{2.7} \mathrm{Se}_{0.3}$ nanoplatelet composites. Nano Lett, 2012, 12: 4305-4310

8 Zhou C, Lee YK, Cha J, et al. Defect engineering for high-performance n-type PbSe thermoelectrics. J Am Chem Soc, 2018, 140: 9282-9290

9 Li Z, Xiao C, Zhu H, et al. Defect chemistry for thermoelectric materials. J Am Chem Soc, 2016, 138: 14810-14819

10 Biswas K, He J, Blum ID, et al. High-performance bulk thermoelectrics with all-scale hierarchical architectures. Nature, 2012, 489: 414-418

11 Zhao LD, Dravid VP, Kanatzidis MG. The panoscopic approach to high performance thermoelectrics. Energy Environ Sci, 2014, 7: 251-268

12 Chen YK, Chen MC, Zhou LJ, et al. Syntheses, structures, and nonlinear optical properties of quaternary chalcogenides: $\mathrm{Pb}_{4} \mathrm{Ga}_{4} \mathrm{GeQ}_{12}$ (Q = S, Se). Inorg Chem, 2013, 52: 8334-8341

13 Li G, Wu K, Liu Q, et al. $\mathrm{Na}_{2} \mathrm{ZnGe}_{2} \mathrm{~S}_{6}$ : A new infrared nonlinear optical material with good balance between large second-harmonic generation response and high laser damage threshold. J Am Chem Soc, 2016, 138: 7422-7428

14 Mei D, Yin W, Feng K, et al. $\mathrm{LiGaGe}_{2} \mathrm{Se}_{6}$ : A new IR nonlinear optical material with low melting point. Inorg Chem, 2012, 51: 1035-1040

15 Li GM, Liu Q, Wu K, et al. $\mathrm{Na}_{2} \mathrm{CdGe}_{2} \mathrm{Q}_{6}(\mathrm{Q}=\mathrm{S}$, Se): two metalmixed chalcogenides with phase-matching abilities and large second-harmonic generation responses. Dalton Trans, 2017, 46: 2778-2784

16 Feng $\mathrm{K}$, Wang $\mathrm{W}$, He $\mathrm{R}$, et al. $\mathrm{K}_{2} \mathrm{FeGe}_{3} \mathrm{Se}_{8}$ : $\mathrm{A}$ new antiferromagnetic iron selenide. Inorg Chem, 2013, 52: 2022-2028

17 Lin Z, Li C, Kang L, et al. $\mathrm{SnGa}_{2} \mathrm{GeS}_{6}$ : synthesis, structure, linear and nonlinear optical properties. Dalton Trans, 2015, 44: 74047410

18 Aitken JA, Larson P, Mahanti SD, et al. $\mathrm{Li}_{2} \mathrm{PbGeS}_{4}$ and $\mathrm{Li}_{2} \mathrm{EuGeS}_{4}$ : Polar chalcopyrites with a severe tetragonal compression. Chem Mater, 2001, 13: 4714-4721

19 McGuire MA, Scheidemantel TJ, Badding JV, et al. $\mathrm{Tl}_{2} \mathrm{AXTe}_{4}(\mathrm{~A}=$ $\mathrm{Cd}, \mathrm{Hg}, \mathrm{Mn} ; \mathrm{X}=\mathrm{Ge}, \mathrm{Sn})$ : Crystal structure, electronic structure, and thermoelectric properties. Chem Mater, 2005, 17: 6186-6191

20 Li G, Zhen $\mathrm{N}$, Chu $\mathrm{Y}$, et al. $\mathrm{Li}_{3} \mathrm{Ge}_{3} \mathrm{Se}_{6}$ : the first ternary lithium germanium selenide with interesting ${ }_{\infty}\left[\mathrm{Ge}_{6} \mathrm{Se}_{12}\right]_{\mathrm{n}}$ chains constructed by ethane-like $\left[\mathrm{Ge}_{2} \mathrm{Se}_{6}\right]^{6-}$ clusters. Dalton Trans, 2017, 46: 16399-16403

21 Wu K, Yang Z, Pan S. $\mathrm{Na}_{4} \mathrm{MgM}_{2} \mathrm{Se}_{6}(\mathrm{M}=\mathrm{Si}, \mathrm{Ge})$ : The first noncentrosymmetric compounds with special ethane-like $\left[\mathrm{M}_{2} \mathrm{Se}_{6}\right]^{6-}$ units exhibiting large laser-damage thresholds. Inorg Chem, 2015, 54: $10108-10110$

22 Cui Y, Assoud A, Kleinke H. Synthesis and structural and physical properties of new semiconducting quaternary tellurides: $\mathrm{Ba}_{4} \mathrm{Ag}_{3.95} \mathrm{Ge}_{2} \mathrm{Te}_{9}$ and $\mathrm{Ba}_{4} \mathrm{Cu}_{3.71} \mathrm{Ge}_{2} \mathrm{Te}_{9}$. Inorg Chem, 2009, 48: 53135319

23 Choudhury A, Strobel S, Martin BR, et al. Synthesis of a family of solids through the building-block approach: A case study with $\mathrm{Ag}^{+}$ substitution in the ternary Na-Ge-Se system.. ChemInform, 2007, 38

24 Choudhury A, Ghosh K, Grandjean F, et al. Structural, optical, and magnetic properties of $\mathrm{Na}_{8} \mathrm{Eu}_{2}\left(\mathrm{Si}_{2} \mathrm{~S}_{6}\right)_{2}$ and $\mathrm{Na}_{8} \mathrm{Eu}_{2}\left(\mathrm{Ge}_{2} \mathrm{~S}_{6}\right)_{2}$ : Europium(II) quaternary chalcogenides that contain an ethane-like $\left(\mathrm{Si}_{2} \mathrm{~S}_{6}\right)^{6-}$ or $\left(\mathrm{Ge}_{2} \mathrm{~S}_{6}\right)^{6-}$ moiety. J Solid State Chem, 2015, 226: 74-80

25 Marking GA, Kanatzidis MG. The ethane-like $\left[\mathrm{Ge}_{2} \mathrm{~S}_{6}\right]^{6-}$ and $\left(\mathrm{Si}_{2} \mathrm{Se}_{6}\right)^{6-}$ metals in $\mathrm{Na}_{8} \mathrm{~Pb}_{2}\left[\mathrm{Ge}_{2} \mathrm{~S}_{6}\right]_{2}, \mathrm{Na}_{8} \mathrm{Sn}_{2}\left[\mathrm{Ge}_{2} \mathrm{~S}_{6}\right]_{2}$, and $\mathrm{Na}_{8} \mathrm{~Pb}_{2}\left[\mathrm{Si}_{2} \mathrm{Se}_{6}\right]_{2}$. J Alloys Compd, 1997, 259: 122-128

$26 \mathrm{Wu} \mathrm{X}, \mathrm{Hu} \mathrm{Y}$, Pan $\mathrm{H}$, et al. $\mathrm{Na}_{9} \mathrm{Sb}\left(\mathrm{Ge}_{2} \mathrm{Q}_{6}\right)_{2}(\mathrm{Q}=\mathrm{S}$, Se): two new antimony(III) quaternary chalcogenides with ethane-like $\left[\mathrm{Ge}_{2} \mathrm{Q}_{6}\right]^{6-}$ ligands. RSC Adv, 2016, 6: 99475-99481

27 Zhang CY, Zhou LJ, Chen L. Quaternary tellurides with different valent Ge centers: $\mathrm{Cs}_{2} \mathrm{Ge}_{3} \mathrm{M}_{6} \mathrm{Te}_{14}(\mathrm{M}=\mathrm{Ga}$, In). Inorg Chem, 2012, 51: 7007-7009

28 Palchik O, Marking GM, Kanatzidis MG. Exploratory synthesis in molten salts: Role of flux basicity in the stabilization of the complex thiogermanates $\mathrm{Cs}_{4} \mathrm{~Pb}_{4} \mathrm{Ge}_{5} \mathrm{~S}_{16}, \quad \mathrm{~K}_{2} \mathrm{PbGe}_{2} \mathrm{~S}_{6}, \quad$ and $\mathrm{K}_{4} \mathrm{Sn}_{3} \mathrm{Ge}_{3} \mathrm{~S}_{14}$. Inorg Chem, 2005, 44: 4151-4153 
29 Poling SA, Nelson CR, Sutherland JT, et al. Crystal structure of thiogermanic acid $\mathrm{H}_{4} \mathrm{Ge}_{4} \mathrm{~S}_{10}$. Inorg Chem, 2003, 42: 7372-7374

30 Wu YY, Xiong L, Jia F, et al. $\mathrm{Cs}_{2} \mathrm{Ge}_{3} \mathrm{In}_{6} \mathrm{Se}_{14}$ : A structure transformation driven by the size preference and its properties. Inorg Chem, 2018, 57: 4667-4672

31 Sheldrick GM. SHELXTL, version 5.1. Bruker-AXS: Madison, WI, 1998

32 Spek AL. Single-crystal structure validation with the program PLATON. J Appl Crystlogr, 2003, 36: 7-13

33 Kresse G, Furthmüller J. Efficient iterative schemes for ab initio total-energy calculations using a plane-wave basis set. Phys Rev B, 1996, 54: 11169-11186

34 Perdew JP, Burke K, Ernzerhof M. Generalized gradient approximation made simple. Phys Rev Lett, 1996, 77: 3865-3868

35 Kresse G, Joubert D. From ultrasoft pseudopotentials to the projector augmented-wave method. Phys Rev B, 1999, 59: 1758-1775

36 Blöchl PE. Projector augmented-wave method. Phys Rev B, 1994, 50: $17953-17979$

37 Parliñski K. Software phonon, cracow (2001) as implemented in medeA 2.2. Materials Design, Angel Fire, New Mexico, 2005

38 Anderson MW, Gebbie-Rayet JT, Hill AR, et al. Predicting crystal growth via a unified kinetic three-dimensional partition model. Nature, 2017, 544: 456-459

39 Rak M, Izdebski M, Brozi A. Kinetic Monte Carlo study of crystal growth from solution. Comput Phys Commun, 2001, 138: 250-263

40 Cuppen HM, van Veenendaal E, van Suchtelen J, et al. A Monte Carlo study of dislocation growth and etching of crystals. J Cryst Growth, 2000, 219: 165-175

41 Wei L, Lv X, Yang Y, et al. Theoretical investigation on the microscopic mechanism of lattice thermal conductivity of $\mathrm{ZnXP}_{2}(\mathrm{X}=$ $\mathrm{Si}, \mathrm{Ge}$, and Sn). Inorg Chem, 2019, 58: 4320-4327

42 Garg J, Bonini N, Marzari N. High thermal conductivity in shortperiod superlattices. Nano Lett, 2011, 11: 5135-5141

43 Shaabani L, Aminorroaya-Yamini S, Byrnes J, et al. Thermoelectric performance of Na-doped GeSe. ACS Omega, 2017, 2: 9192-9198

44 Ibáñez $\mathrm{M}$, Zamani $\mathrm{R}$, LaLonde $\mathrm{A}$, et al. $\mathrm{Cu}_{2} \mathrm{ZnGeSe}_{4}$ nanocrystals: Synthesis and thermoelectric properties. J Am Chem Soc, 2012, 134: 4060-4063

45 Perez CJ, Bates VJ, Kauzlarich SM. Hydride synthesis and thermoelectric properties of type-I clathrate $\mathrm{K}_{8} \mathrm{E}_{8} \mathrm{Ge}_{38}(\mathrm{E}=\mathrm{Al}, \mathrm{Ga}$, In). Inorg Chem, 2019, 58: 1442-1450

46 Pavan Kumar V, Paradis-Fortin L, Lemoine P, et al. Designing a thermoelectric copper-rich sulfide from a natural mineral: Synthetic germanite $\mathrm{Cu}_{22} \mathrm{Fe}_{8} \mathrm{Ge}_{4} \mathrm{~S}_{32}$. Inorg Chem, 2017, 56: 1337613381

47 Nuss J, Wedig U, Xie W, et al. Phosphide-tetrahedrite $\mathrm{Ag}_{6} \mathrm{Ge}_{10} \mathrm{P}_{12}$ : Thermoelectric performance of a long-forgotten silver-cluster compound. Chem Mater, 2017, 29: 6956-6965

$48 \mathrm{Fu}$ J, Su X, Zheng Y, et al. Thermoelectric properties of Ga/Ag codoped type-III $\mathrm{Ba}_{24} \mathrm{Ge}_{100}$ clathrates with in situ nanostructures. ACS Appl Mater Interfaces, 2015, 7: 19172-19178

49 Heinrich CP, Day TW, Zeier WG, et al. Effect of isovalent substitution on the thermoelectric properties of the $\mathrm{Cu}_{2} \mathrm{ZnGeSe}_{4-x} \mathrm{~S}_{x}$ series of solid solutions. J Am Chem Soc, 2014, 136: 442-448

50 Chen $\mathrm{H}$, Chen $\mathrm{YK}$, Lin $\mathrm{H}$, et al. Quaternary layered semiconductor $\mathrm{Ba}_{2} \mathrm{Cr}_{4} \mathrm{GeSe}_{10}$ : Synthesis, crystal structure, and thermoelectric properties. Inorg Chem, 2018, 57: 916-920

51 Kurosaki K, Kosuga A, Muta $\mathrm{H}$, et al. $\mathrm{Ag}_{9} \mathrm{TlTe}_{5}$ : A high-performance thermoelectric bulk material with extremely low thermal conductivity. Appl Phys Lett, 2005, 87: 061919
52 Wan CL, Pan W, Xu Q, et al. Effect of point defects on the thermal transport properties of $\left(\mathrm{La}_{x} \mathrm{Gd}_{1-x}\right)_{2} \mathrm{Zr}_{2} \mathrm{O}_{7}$ : Experiment and theoretical model. Phys Rev B, 2006, 74: 144109

53 Liu H, Shi X, Xu F, et al. Copper ion liquid-like thermoelectrics. Nat Mater, 2012, 11: 422-425

54 Ouyang $\mathrm{T}$, Zhang $\mathrm{X}, \mathrm{Hu} \mathrm{M}$. Thermal conductivity of ordereddisordered material: a case study of superionic $\mathrm{Ag}_{2} \mathrm{Te}$. Nanotechnology, 2015, 26: 025702

55 Jiang B, Qiu P, Eikeland E, et al. $\mathrm{Cu}_{8} \mathrm{GeSe}_{6}$-based thermoelectric materials with an argyrodite structure. J Mater Chem C, 2017, 5: 943-952

56 Zhao LD, Lo SH, Zhang Y, et al. Ultralow thermal conductivity and high thermoelectric figure of merit in SnSe crystals. Nature, 2014, 508: $373-377$

57 Skoug EJ, Cain JD, Morelli DT. Structural effects on the lattice thermal conductivity of ternary antimony- and bismuth-containing chalcogenide semiconductors. Appl Phys Lett, 2010, 96: 181905

58 Cahill DG, Watson SK, Pohl RO. Lower limit to the thermal conductivity of disordered crystals. Phys Rev B, 1992, 46: 61316140

Acknowledgements This research was supported by the National Natural Science Foundation of China (21975032 and 21571020), and the National Key Research and Development Program of China (2018YFA0702100). The room temperature ultrasonic pulse echo measurements were performed by Dr. Yu Xiao and Prof. Li-Dong Zhao from the School of Materials Science and Engineering, Beihang University, Beijing, China. Their great help was sincerely appreciated.

Author contributions Chen $\mathrm{L}, \mathrm{Wu} \mathrm{LM}$, and $\mathrm{Ma} \mathrm{N}$ proposed the outline of the manuscript and wrote the paper. All authors discussed and revised the manuscript.

Conflict of interest The authors declare no conflict of interest.

Supplementary information Details of crystallography data, TG and DSC, detailed XRD patterns and calculated band structures, photographs of crystals, XPS, Raman and UV-vis diffuse-reflectance spectra, electron localization function and EDS analyses are available in the online version.

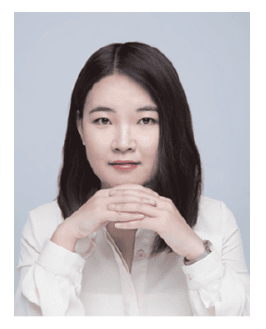

Ni Ma received her BSc degree from the College of Science, Northeast Forestry University in 2015. Now, she is a $\mathrm{PhD}$ candidate under the supervision of Prof. Li-Ming Wu in the College of Chemistry, Beijing Normal University (BNU). Her research interest focuses on the syntheses of inorganic solid functional materials and their applications in energy conversion. 


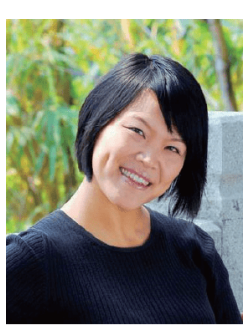

Ling Chen received her MSc from BNU in 1996 and $\mathrm{PhD}$ degree in Fujian Institute of Research on the Structure of Matter (FJIRSM), Chinese Academy of Sciences (CAS) in 1999, and carried out her postdoc research in Iowa State University, USA in 2000-2003. She joined the faculty of FJIRSM in 2003 as a full professor, and moved to BNU in 2015. Her research focuses on the exploration of solid-state compounds, and their nonlinear optical properties and thermoelectric properties.

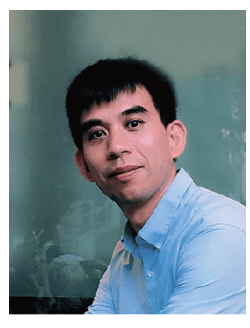

Li-Ming Wu received his BSc and MSc degrees from BNU in 1993 and 1996, and $\mathrm{PhD}$ degree from Fuzhou University in 1999, and carried out his postdoctoral research in CAS (1999-2001) and Arizona State University, USA (2001-2004). $\mathrm{Wu}$ started his own research group as a full professor in 2004 in FJIRSM, CAS, and moved to BNU in 2015. His interests focus on the inorganic solid functional materials and theoretical chemistry of solids.

\section{低热导率新机制一 $\mathrm{Cs}_{2} \mathrm{Ge}_{3} \mathrm{Ga}_{6} \mathrm{Se}_{14}$ 中异价锗离子的 振动弱塊合性}

马妮 ${ }^{1}$, 熊琳 ${ }^{2}$, 陈玲 ${ }^{{ }^{*}}$, 吴立明 ${ }^{2^{*}}$

摘要 热管理是电子器件小型化和功率密度提高的关键, 因此研究 材料热输运性质及声子传输机制具有非常重要的意义. 本文报道 了一例含多价态锗 $\left(\mathrm{Ge}^{3+}, \mathrm{Ge}^{2+}\right)$ 的新型硒化物, $\mathrm{Cs}_{2} \mathrm{Ge}_{3} \mathrm{Ga}_{6} \mathrm{Se}_{14}$. 单晶 结构衍射数据表明, 化合物中不同价态锗分别采用 $\left(\mathrm{Ge}^{3+}\right)_{2} \mathrm{Se}_{6}$ 二聚 体或 $\left(\mathrm{Ge}^{2+}\right) \mathrm{Se}_{6}$ 八面体的配位模式, 323-773 K范围内, 其热导率测试 值为 $0.57-0.48 \mathrm{~W} \mathrm{~m}^{-1} \mathrm{~K}^{-1}$, 该值是目前已知含锗固体材料中的最低 值, 接近其玻璃态极限值. 更重要的是, 我们发现由于不同价态锗离 子振动模式之间存在弱耦合性, 使得热振动能量无法在两种结构 单元之间有效传递，从而降低了化合物热导率. 这种机制在材料热 导率研究领域尚属首次发现. 本文还通过结构因子 $f_{i}=\sin (180-\beta) \times$ $d_{\mathrm{Ge}-\mathrm{O}} / l_{i}(i=A, B)$ 的大小, 给出了 $\mathrm{Cs}_{2} \mathrm{Ge}_{3} \mathrm{M}_{6} \mathrm{Q}_{14}$ 家族的晶体结构分布 规律. 